\title{
Health Burden and Economic Impacts Attributed to PM2.5 and 03 in China from 2010 to 2050 under Different Representative Concentration Pathway Scenarios
}

\section{Yiyi Wang}

Nanjing University of Information Science and Technology jianlin $\mathrm{Hu}$

Nanjing University of Information Science and Technology Jia Zhu

Nanjing University of Information Science and Technology Jingyi Li

Nanjing University of Information Science and Technology

Momei Qin

Nanjing University of Information Science and Technology

Hong Liao

Nanjing University of Information Science and Technology

Kai Chen

Yale University School of Public Health

Meng Wang ( $\triangle$ mwang54@buffalo.edu )

University at Buffalo School of Public Health and Health Professions https://orcid.org/0000-00032085-6191

\section{Research}

Keywords: PM2.5, 03, premature mortality, China, Representative Concentration Pathway scenarios

Posted Date: February 23rd, 2021

DOl: https://doi.org/10.21203/rs.3.rs-225248/v1

License: (9) (1) This work is licensed under a Creative Commons Attribution 4.0 International License. Read Full License 


\section{Health Burden and Economic Impacts Attributed to $\mathrm{PM}_{2.5}$ and $\mathrm{O}_{3}$}

2 in China from 2010 to 2050 under Different Representative

3 Concentration Pathway Scenarios

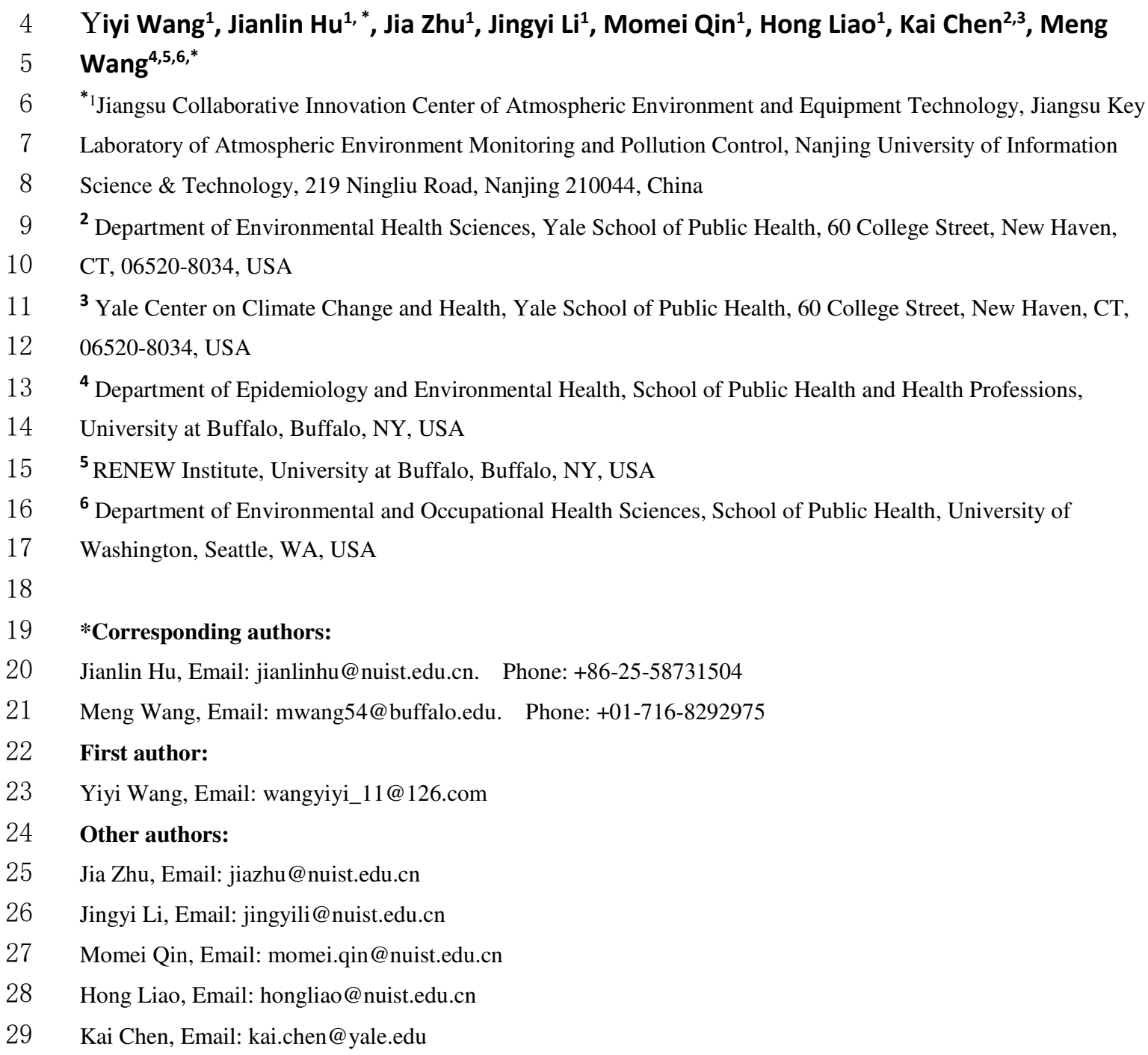




\section{Abstract:}

Background: Quantifying future health burden attributed to fine particulate matters $\left(\mathrm{PM}_{2.5}\right)$ and ozone $\left(\mathrm{O}_{3}\right)$ in China is challenging when jointly accounting for emissions, climate and population changes. Future health burdens caused by $\mathrm{PM}_{2.5}$ and $\mathrm{O}_{3}$ in China remain largely understudied.

Methods: In this paper, we used the Goddard Earth Observing System chemical transport model (GEOS-Chem) to project $\mathrm{PM}_{2.5}$ and $\mathrm{O}_{3}$ concentrations from 2010 to 2050 under four Representative Concentration Pathway scenarios (RCPs), then projected the $\mathrm{PM}_{2.5}$ and $\mathrm{O}_{3}$-related premature mortality and years of life lost (YLL) in this period. We then estimated the resulting economic burdens such as medical expenses (ME) and value of statistical life (VSL) in 2010-2050 attributed to the burdens of disease on $\mathrm{PM}_{2.5}$ and $\mathrm{O}_{3}$.

Results: Compared to the targeted year 2050, we found that $\mathrm{PM}_{2.5}$ concentrations changed between $-31.5 \%$ to $14.5 \%$ since 2010 , resulted in $-13.5 \%$ to $9.4 \%$ change in $\mathrm{PM}_{2.5}$-related mortality and $-25.7 \%$ to $0.6 \%$ change in YLL across all the RCPs scenarios. For $\mathrm{O}_{3}$, the concentrations varied $-13.3 \%$ to $3.7 \%$ by 2050 , contributing to $26.9 \%$ to $13.1 \%$ change in $\mathrm{O}_{3}$-related mortality and $-48.8 \%$ to $4.0 \%$ change in YLL. The lowest health impacts occurred in the RCP4.5 scenario by 2050 for both pollutants. In 2010, the ME caused by $\mathrm{PM}_{2.5}$ and $\mathrm{O}_{3}$ was $\$ 6.3-6.5$ billion, and the VSL was $\$ 112.1$ 114.9 billion, accounting for 2.9-3.0\% of the total GDP ( $\$ 3874$ billion). By 2050, ME and VSL will change from $-19.7 \%$ to $17.5 \%$ and from $-65.5 \%$ to $136.6 \%$, respectively. 
Conclusion: This study suggested that future $\mathrm{PM}_{2.5}$ and $\mathrm{O}_{3}$ under certain $\mathrm{RCP}$ scenarios can have large health and economic benefits. However, given that the future population will always be higher than the baseline in 2010 , more aggressive air pollution mitigation measures are needed for China.

Keywords: $\mathrm{PM}_{2.5} ; \mathrm{O}_{3}$; premature mortality; China; Representative Concentration Pathway scenarios

8

(1)

0

61

62

63

64

65

66

67

68

69

70




\section{Background}

A large number of epidemiological studies had shown that fine particulate matters $\left(\mathrm{PM}_{2.5}\right)$ and ozone $\left(\mathrm{O}_{3}\right)$ contributed to premature mortality from chronic or acute diseases, including respiratory and cardiovascular diseases [1-6]. The Global Burden of Diseases Study found that the $\mathrm{PM}_{2.5}$ and $\mathrm{O}_{3}$ caused 4.2 million and 0.25 million premature deaths globally in 2015, respectively [7], with 39\% [8] of $\mathrm{PM}_{2.5}$ and 32\% [9] of $\mathrm{O}_{3}$ attributed to China alone. Nearly $86 \%$ of the population in China was exposed to $\mathrm{PM}_{2.5}$ with a daily concentration higher than $75 \mu \mathrm{g} / \mathrm{m}^{3}$ of the Grade II Chinese Ambient Air Quality Standards (CAAQS) in 2015 [7]. A recent report demonstrated that $\mathrm{O}_{3}$ concentrations in all major Chinese metropolitan regions are more than $10 \%$ higher than the CAAQS level $\left(160 \mu \mathrm{g} / \mathrm{m}^{3}\right)$ [10]. The adverse health impacts of $\mathrm{PM}_{2.5}$ and $\mathrm{O}_{3}$ pollution had placed a huge burden on economic development in China [11, 12].

Projecting future pollution changes and their impacts on health is challenging because of uncertainties in the changes of future emissions, climate and population. A few studies had attempted to quantify the health impacts under specific future policy scenarios. For instance, Maji et al (2018) [13] projected the potential health benefits by 2020 according to the concentration of $\mathrm{PM}_{2.5}$ in policy scenarios (WHO IT-1: $35 \mu \mathrm{g} / \mathrm{m}^{3}$, IT-2: $25 \mu \mathrm{g} / \mathrm{m}^{3}$, IT-3: $15 \mu \mathrm{g} / \mathrm{m}^{3}$ and AQG: $10 \mu \mathrm{g} / \mathrm{m}^{3}$ et al.). Wang et al (2019) [14] projected $\mathrm{PM}_{2.5}$-related premature mortality in 2010, 2020 and 2030 using the target $\mathrm{PM}_{2.5}$ concentration proposed

(13th FiveYear Plan for Environmental Conservation). These studies set several future target 
pollutant concentrations that were not linked to pollutant emissions in the context of climate change.

In this study, we used the Goddard Earth Observing System chemical transport model (GEOS-Chem) to projected changes in $\mathrm{PM}_{2.5}$ and $\mathrm{O}_{3}$ concentrations in China under four Representative Concentration Pathway (RCP) from 2010 to 2050 and evaluated the impacts of air quality changes under different RCP scenarios on future premature death burden. RCP scenarios generated a series of future scenarios representing different levels of emission changes. This study primarily focused on health and economic consequences from air pollution emission changes, as a few studies had revealed that the $21^{\text {st }}$-century air quality forecast range was mainly driven by changes of emissions rather than climate $[15,16]$.

\section{Methods}

\section{1 $\mathrm{PM}_{2.5}$ and $\mathrm{O}_{3}$ data}

Annual average concentrations of $\mathrm{PM}_{2.5}$ and $\mathrm{O}_{3}$ were projected in China from 2010 to 2050 , with the year 2010 as the baseline period using a nested grid capability of GEOS-Chem 9.1.3 model (http://acmg.seas.harvard.edu/geos/). The model was driven by assimilated meteorological data from the Goddard Earth Observation System (GEOS) of NASA's Global Modeling and Assimilation Office. The simulation domain was nested over Asia $\left(11^{\circ} \mathrm{S}-55^{\circ} \mathrm{N}, 70^{\circ}-150^{\circ} \mathrm{E}\right)$, with a horizontal resolution of $0.5^{\circ} \times 0.667^{\circ}(50 \times 66.7 \mathrm{~km})$ and 47 vertical layers up to $0.01 \mathrm{hPa} . \mathrm{PM}_{2.5}$ was estimated as the total mass of each component of $\mathrm{PM}_{2.5}$ from the GEOS-Chem model. Specific 
details were showed in $\mathrm{Li}$ et al (2016) [17]. $\mathrm{O}_{3}$ concentrations were estimated by emissions of $\mathrm{O}_{3}$ precursors, aerosol precursors, and aerosols, and the specific details were showed in Zhu et al (2016) [18]. GEOS-Chem model had successfully reproduced the spatial-temporal distribution of $\mathrm{O}_{3}[19]$ and $\mathrm{PM}_{2.5}$ [20] concentrations in China. $\mathrm{Li}$ et al (2016) [17] compared $\mathrm{PM}_{2.5}$ model predictions with the observational data in five cities in 2010 under four RCP scenarios, and found high agreement between the predictions and observations, i.e. correlation coefficients were $0.50-0.70$, and the normalized mean deviations (NMB) were -31\%-39\%. Similarly, Zhu et al (2016) [18] compared measured and simulated $\mathrm{O}_{3}$ concentration at ten stations in 2000 under the RCP4.5 scenario. The observed correlation coefficient was 0.76 and the normalized mean deviation (NMB) was $+11.6 \%$.

Four RCPs warming scenarios (i.e. RCP2.6, RCP4.5, RCP6.0 and RCP8.5) were used to project the $\mathrm{PM}_{2.5}$ and $\mathrm{O}_{3}$ concentrations since the year of 2010 for every decade through 2050. The RCPs is the basis for future climate change projection proposed by the IPCC's fourth assessment report, each of which represents a representative scenario of radiation forcing stabilization at $2.6 \mathrm{~W} / \mathrm{m}^{2}, 4.5 \mathrm{~W} / \mathrm{m}^{2}, 6.0 \mathrm{~W} / \mathrm{m}^{2}$ or $8.5 \mathrm{~W} / \mathrm{m}^{2}$ by 2100 , respectively. Among the scenarios, $\mathrm{RCP} 8.5$ was considered as a global high greenhouse gas emission scenario without mitigation measures, followed by RCP6.0, RCP4.5, and RCP2.6 [21]. Therefore, it is expected that the consequent global temperature may rise by $4.1^{\circ} \mathrm{C}, 2.2^{\circ} \mathrm{C}, 1.7^{\circ} \mathrm{C}$ and $0.9^{\circ} \mathrm{C}$ until 2050 by different RCPs, as compared to that in 2000 [5].

\subsection{Population data}


were obtained from United Nations, Department of Economic and Social Affairs,

140 Population Division: World Population Prospects: The 2019 Revision. (Medium variant)

141 (https://www.populationpyramid.net/china).

Gridded population data in 2010 census at $1 \mathrm{~km}$ resolution were obtained from the

Oak

Ridge Nation

Laboratory's

LandScan

database

(https://landscan.ornl.gov/downloads/2008) and gridded to fit the GEOS-Chem model resolution. were estimated for each decade starting from 2010 to 2050 according the equation 1 . Ischemic heart disease (IHD, I20-I25), stroke（I60-I69） and Lung cancer (LC, C34) [22], then summed up to represent the total deaths in each decade. For $\mathrm{O}_{3}$ concentration, evidence that $\mathrm{O}_{3}$ is causally or likely to be causally associated with death from other diseases [23]

$$
\Delta \text { Mort }=\sum_{i=1}^{n} p o p_{i} * y_{0}\left[\left(\mathrm{RR}_{i, j}-1\right) / \mathrm{RR}_{i, j}\right]
$$

Where $\Delta$ Mort is premature mortality caused by $\mathrm{PM}_{2.5}$ or $\mathrm{O}_{3}, p o p_{i}$ is the 
population for grid $\mathrm{i}, \mathrm{RR}_{i, j}$ is relative risk for a disease $\mathrm{j}$ at a grid $\mathrm{i}$ caused by $\mathrm{PM}_{2.5}$ or $\mathrm{O}_{3}$, and (RR-1)/RR is the attributable fraction, $y_{0}$ is the baseline mortality of particular disease categories, obtained from China Health Statistics Yearbook [24].

The RRs of $\mathrm{PM}_{2.5}$ exposure for different disease categories were estimated using an integrated exposure-response (IER) by Burnett et al [25, 26].

$$
\begin{gathered}
\mathrm{RR}_{i, j}=1 \quad C \leq C_{0} \\
\mathrm{RR}_{i, j}=1+\alpha_{j}\left\{1-\exp \left(-\gamma_{j}\left(C-C_{0}\right)^{\delta_{j}}\right\} \quad C>C_{0}\right.
\end{gathered}
$$

Where $\alpha_{j}, \gamma_{j}$, and $\delta_{j}$ are obtained through the average of 1000 sets of fitting parameters by Burnett et al (2014) [26]. C is the projected $\mathrm{PM}_{2.5}$ concentrations under different RCPs scenarios, $\mathrm{C}_{0}$ is the theoretical minimum-risk concentrations of 5.8 $\mu \mathrm{g} / \mathrm{m}^{3}$ as used in GDB 2010 [27].

The $\mathrm{RR}$ of $\mathrm{O}_{3}$ related mortality risk by disease categories was calculated using the log-linear exposure-response function by Jerrett et al (2009) [28]

$\mathrm{RR}_{i, j}=\exp \left(\beta \times\left(X-X_{0}\right)\right)$

Where, $\beta$ is a coefficient estimated based on the associations of ozone concentration with CVD and respiratory mortality from the estimates of the multipollutant model, which simultaneously adjusted for $\mathrm{PM}_{2.5}$ and $\mathrm{NO}_{2}$ [29]. $\mathrm{X}$ is the concentration of $\mathrm{O}_{3}, \mathrm{X}_{0}$ is a theoretical of $26.7 \mathrm{ppb}$ based on the minimum ozone exposure from the study of Turner et al (2016) [29].

The corresponding YLL was calculated as follows:

$$
\Delta \mathrm{YLL}=\sum \Delta \mathrm{Mort}_{t} \times \mathrm{LE}_{t} .
$$

Where $\triangle \mathrm{YLL}$ is YLL caused by $\mathrm{PM}_{2.5}$ or $\mathrm{O}_{3}$ at a specific age $\mathrm{t}$ group, $\mathrm{LE}_{t}$ is the 
life expectancy at a specific age $t$ group from 2010 to 2050 the was shown in table S1 (https://population.un.org/wpp/Download/).

The calculation of premature mortality under future scenarios had jointly accounted for the effects of exposure to pollutant concentrations due to emission changes and population size. To study the independent contribution of premature deaths from each determinant, we mutually controlled one factor constant to project the impact of the other determinant on future change in mortality.

\subsection{Economic impacts}

We estimated economic impact from air pollution changes based on two factors: 1) the total medical expenditure (ME), which refers to any expenses incurred to prevent or treat injuries or diseases; 2) the value of a statistical life (VSL) which indicates how much an individual is willing to pay (WTP) for reducing the risk of death. It is widely used in cost-benefit analysis in the United States and Europe to evaluate the benefits of savings [30]. The ME and VSL caused by premature death were calculated for each province in China.

$$
M E_{\mathrm{p}, \mathrm{s}, \mathrm{y}}=\sum_{1}^{p} \Delta \operatorname{Mort}_{p, s, y} \times\left(\mathrm{GDP}_{p, y} \times \beta_{p}+\delta_{p}\right)
$$

Where, $M E_{\mathrm{p}, \mathrm{s}, \mathrm{y}}$ is the medical expenses [billion dollar/year] for the province $\mathrm{p}$, scenario s and year y. $\beta_{p}$ and $\delta_{p}$ are the parameters of medical service price by Xie et al (2016) [31]. GDP $\operatorname{GD}_{p, y}$ is the per capita GDP for the province $\mathrm{p}$ at year $\mathrm{y}$ (https://www.pwc.com.tr/tr/publications/arastirmalar/assets/world-in-2050/2050-dedunya-raporu.pdf).

$$
V S L_{\mathrm{p}, \mathrm{s}, \mathrm{y}}=\sum_{1}^{p} \mathrm{WTP} \times \Delta \operatorname{Mort}_{p, s, y} \times\left(\frac{G D P_{p, y}}{G D P_{2010, \text { China }}}\right)^{0.5}
$$


Where, $V S L_{\mathrm{p}, \mathrm{s}, \mathrm{y}}$ is the value of statistical life. $\mathrm{GDP}_{2010 \text {, China }}$ is the national average

per capita GDP in 2010. WTP is 250,000 dollars in 2010, which is a willingness $t$ to pay for avoiding premature mortality [32]. The assumption of future GDP is consistent with 2010 .

\section{Results}

\subsection{Future PM2.5 and $\mathrm{O}_{3}$ Concentrations and Population Projection}

Figure 1(a) and Figure 1(b) showed the change of annual average concentrations of $\mathrm{PM}_{2.5}$ and $\mathrm{O}_{3}$ by decades between 2010-2050 under four different RCP scenarios. In Figure 1(a), an inverse U-shape pattern of $\mathrm{PM}_{2.5}$ variations were observed under the RCP2.6, 4.5 and 8.0 scenarios across the period with peak level shown in 2020 or 2030 and the lowest level occurred in 2050. For the RCP6.0 scenario, an elevated trend was noted throughout the years. This is consistent to the temporal variations of the major air pollutants' emissions which showed increase trends under the RCP6.0 (e.g. $\mathrm{SO}_{2}, \mathrm{NOx}$, $\mathrm{NH}_{3}$, OC and BC) starting the year of $2010-2030$ as compared to the declining pattern of the emissions in the other scenarios (Figure S5). Among different scenarios, the RCP4.5 achieved the largest reduction in $\mathrm{PM}_{2.5}$ for about $10 \mu \mathrm{g} / \mathrm{m}^{3}$ as compared to the baseline $\mathrm{PM}_{2.5}$ levels. On the contrary, $\mathrm{O}_{3}$ projections decreased consistently under the RCP2.6 and RCP4.5 scenarios, but increased under the RCP6.0 and RCP8.5. Overall, $\mathrm{PM}_{2.5}$ concentrations decreased by $6.3-11.1 \mu \mathrm{g} / \mathrm{m}^{3}$ under the RCP2.6, 4.5 and 8.5 scenarios until 2050 from baseline, and $\mathrm{O}_{3}$ concentrations decreased by 3.7-6.1 ppb under RCP2.6 and RCP4.5 scenarios. The magnitude of reduction for $\mathrm{PM}_{2.5}$ 
concentrations is comparable to a previous study in Eastern China suggesting about 1$8 \mu \mathrm{g} / \mathrm{m}^{3}$ lower for $\mathrm{PM}_{2.5}$ in 2050 than that in 2000 under the RCP2.6, 4.5 and 8.5 scenarios [16] and for $\mathrm{O}_{3}$ concentration, a reduction by 7 to 6 ppb under RCP4.5 scenarios [33].

The projected spatial distributions of $\mathrm{PM}_{2.5}$ and $\mathrm{O}_{3}$ concentrations by decades were shown in figure S1 and figure S2. By 2050, the largest $\mathrm{PM}_{2.5}$ reduction area $\left(>40 \mu \mathrm{g} / \mathrm{m}^{3}\right)$ was mainly the regions used to be highly industrialized or urbanized, such as the Beijing-Tianjin-Hebei region and the Sichuan Basin (Figure S4 (a)). For $\mathrm{O}_{3}$, significant $\mathrm{O}_{3}$ reduction was observed in the south-central areas of China around the Yangtze River Delta region (Figure S4 (b)).

The population size was estimated to reach a peak by 2030 for 1464 million and then drop down to 1402 million by 2050 (figure 1 (c)). The population was aging significantly from 2010 to 2050, with increased proportion of the elderly group over 75 years old by decades (figure 1 (d)), suggesting increased susceptibility to $\mathrm{PM}_{2.5}$ and $\mathrm{O}_{3}$ for the Chinese population in the future.

\subsection{Estimated premature Mortality and YLL}

Premature mortality for $\mathrm{PM}_{2.5}$ and $\mathrm{O}_{3}$ exposure generally followed the same pattern as for the concentration changes over the decades under the RCPs (figure 2(a) and figure 2(b)). The largest number of avoided deaths were observed under the RCP4.5 scenario for $\mathrm{PM}_{2.5}$ and the RCP2.6 for $\mathrm{O}_{3}$, which resulted in 254303 and 112900 less deaths by 2050 as compared to the deaths at baseline. Although the reductions of $\mathrm{PM}_{2.5}$ and $\mathrm{O}_{3}$ were spatially different, the resulting largest changes in deaths were consistently 
shown in the Beijing-Tianjin-Hebei region, the Yangtze River Delta and the Sichuan Basin. (figure S4(c-d)).

There were 1886 650-1933 886 deaths caused by $\mathrm{PM}_{2.5}$ in 2010, in which stroke deaths contributed the highest (50.4-50.5\%), followed by deaths from IHD (34.6\%$34.7 \%)$, LC (7.5-7.6\%) and COPD (7.3\%-7.4\%) respectively. By 2050, $\mathrm{PM}_{2.5}$ caused a change of -254333 to 181652 deaths. Except for the RCP6.0 scenario, the relative contribution of IHD to the total deaths increased by $0.8 \%-1.7 \%$, whereas the COPD decreased by $0.4 \%-0.8 \%$ (figure $\mathrm{S} 3(\mathrm{a})$ ). Under the RCP 4.5 scenarios, the mortality caused by COPD, stroke, IHD and LC decreased by $22.9 \%, 9.2 \%, 13.8$ and $22.2 \%$ figure $\mathrm{S} 3(\mathrm{c}))$.

In 2010, there were 385971 (201 197, 562 256) to 423,363 (221 046, 615469$)$ deaths related to $\mathrm{O}_{3}$, and $\mathrm{CVD}$ accounts for $51.7-51.9 \%$ and respiratory accounts for 48.0-48.3\%. By 2050, $\mathrm{O}_{3}$ changed -112900 to 55670 deaths. The changes in the contributions of the two diseases fluctuate slightly $(0.4-0.6 \%)$ (figure $S 3(b))$. Under the RCP2.6 and RCP4.5 scenarios, the mortality associate with each disease was reduced. In the RCP6.0 and RCP8.5 scenarios, the results were opposite (figure S3(d)). Figure 2(c) and Figure 2(d) showed the year of loss (YLL), which reflected the number of years lost due to death before life expectancy, caused by $\mathrm{PM}_{2.5}$ and $\mathrm{O}_{3}$. In 2010 , the YLL caused by $\mathrm{PM}_{2.5}$ exposure is $92.4-94.8$ million. From 2010 to 2020, the number of early death years increased slightly, then decreased for the next 30 years. By 2050, the YLL caused by $\mathrm{PM}_{2.5}$ had decreased by $25.7 \%$ since baseline under the best scenario (i.e. RCP4.5). The trend of YLL caused by $\mathrm{O}_{3}$ was consistent with that of premature 
death from 2010 to 2050 , suggesting about 6.7 million reduced by 2050 under the best scenario (i.e. RCP2.6).

\subsection{Impact of changes in emission and population size on premature mortality}

Figure 3 showed the independent impacts of two factors (emission and population size) on $\mathrm{PM}_{2.5}$ - and $\mathrm{O}_{3}$-related mortality from 2010 to 2050 under four RCP scenarios. The change in $\mathrm{PM}_{2.5}$ concentration while holding the population growth caused a $7.8 \%$ $17.3 \%$ reduction in mortality across all scenarios except the RCP6.0. The population change while maintaining the baseline $\mathrm{PM}_{2.5}$ distribution resulted in $3.8 \%-4.9 \%$ concentration reduction per se contributed to $30.2 \%$ avoided $\mathrm{O}_{3}$-related mortality under the RCP2.6 scenario followed by the $18.0 \%$ under the RCP4.5 scenario. In comparison, increase in population size led to a small increase in $\mathrm{O}_{3}$-related mortality under all scenarios.

\subsection{Provincial mortality changes driven by air pollution changes}

Figure 4 showed the relationships between percent decline in pollutant-related premature deaths that jointly accounted for the impacts of the concentration changes and population growth, and the changes in air pollution by provinces between 2010 and 
Hainan and Yunnan, which suggested that additional factors such as population changes and baseline mortality rate may play an important role in these provinces. Under the RCP4.5 scenario, the number of deaths in Hainan was 0 . This result was due to the sparse population and low pollutant concentration. In provinces, such as Xinjiang, Gansu, Qinghai, Neimeng, where the concentration reduction rate is less than $20 \%$, it was difficult to further reduce the concentration due to the low initial concentration.

\subsection{Economic impact in four RCP scenarios}

Premature mortality caused a GDP loss, including Medical expense (ME) loss and value of statistical life (VSL), which reflected the GDP loss for a family and society, respectively (figure 5). In 2010, $\mathrm{PM}_{2.5}$ caused \$5.8-5.9 billion for ME and \$102.6-104.3 billion for VSL, which was $2.7-2.8 \%$ of GDP in total ( $\$ 3874$ billion). This loss continuously increased to the year of 2020-2030. After that, ME and VSL under the under the RCP4.5 scenario were $4.75 \$$ billion and $\$ 172.11$ billion, respectively. Economic loss caused by ozone was shown in figure 5(b) and figure 5(d). ME and VSL they reduce with time. After 2040, RCP2.6 scenario contributed to the lowest ME (\$0.33 billion) and VSL (around \$12.73 billion).

\section{Discussion}


In this study, we projected China's future $\mathrm{PM}_{2.5}$ and $\mathrm{O}_{3}$-related health burden (premature mortality and YLL) and economic impacts under four RCP scenarios. By 2050, the lowest health burden and smallest economic impacts of $\mathrm{PM}_{2.5}$-related and $\mathrm{O}_{3}$ related occurred in the RCP4.5 scenario, whereas the worst impacts occurred in the RCP6.0 scenario. The change in population size caused the excess mortality rate in 2050 to increase by $3.9 \%-4.9 \%$, partially offsetting the benefits of reducing $\mathrm{PM}_{2.5}$ concentration under emission reduction scenarios.

Few studies had evaluated future changes in $\mathrm{PM}_{2.5}$-related mortality under different climate and emission change scenarios in China. A recent study [33] reported that by $2050, \mathrm{O}_{3}$-related short-term deaths increased under RCP8.5, but decreased under RCP4.5, which was consistent with our findings. The health impact of ozone was far less than $\mathrm{PM}_{2.5}$ pollution. For example, in the RCP4.5 scenario, the death toll caused by $\mathrm{O}_{3}$ (360 958) was $22.1 \%$ of that caused by $\mathrm{PM}_{2.5}$ (1 632 196), and $\mathrm{O}_{3}$ related ME (0.37 billion) was $7.8 \%$ of $\mathrm{PM}_{2.5}$ related ME (4.75 billion) in 2050 (figure 5(a-b)). However, the per capita expenditure caused by ozone pollution was $\$ 102.5$, which was $35.2 \%$ of the per capita expenditure caused by $\mathrm{PM}_{2.5}$ (\$291.0). This was because bronchodilators used for ozone-related respiratory diseases (mainly COPD) treatment are expensive compared to other diseases related to $\mathrm{PM}_{2.5}[29,34,35]$. Moreover, unlike the large reductions in $\mathrm{PM}_{2.5}$ over the recent years due to clean air actions [36], ozone pollution has been increasing in China [37]. Therefore, the pollution of $\mathrm{O}_{3}$ should be taken seriously. Similarly, a previous study [32] found that per capita expenditure (87 yuan) related to $\mathrm{O}_{3}$ was higher than that of $\mathrm{PM}_{2.5}$ (40 yuan). 
The number of premature deaths in the RCP4.5 scenario by 2050 was the lowest.

RCP4.5 scenario follows the path of achieving the radiation forcing target at the lowest cost. To achieve the expected radiation forcing $\left(4.5 \mathrm{~W} / \mathrm{m}^{2}\right)$ in the future, greenhouse gas emissions need to be limited by changing the energy system, utilizing multi-energy and low-emission energy technologies, and developing carbon capture and geological storage technologies [38]. The Lancet Commission [39] pointed out that emissions of greenhouse gas and pollutants and changes in demographic characteristics will threaten climate change to human health more and more serious. Implementing measures to mitigate air pollutants such as $\mathrm{PM}_{2.5}$ can avoid more premature deaths and loss of related benefits.

The study of the relationship between future deaths and $\mathrm{PM}_{2.5}$ showed that the varied measures should be taken depending on the areas. In some provinces, such as Ningxia, Gansu, Heilongjiang, Qinghai, and Xinjiang, air pollution control technology might not help reduce the impact of pollutants but induced a large economic burden, leading to a negative economic impact. Premature deaths can be reduced more efficiently by reducing pollutant concentrations in Jiangsu, Shandong, and Sichuan due to the high population weighted exposure [6].

In the scenarios of RCP2.6, RCP4.5 and RCP8.5, the decrease in the concentration of $\mathrm{PM}_{2.5}$ result in a decrease in the number of deaths. However, the effects of a population size partically offset the benefits of reduced $\mathrm{PM}_{2.5}$ concentration. It was suggested that elderly were more susceptible to air pollutants than young adults, and thus resulted in higher risk of pollution related death [40]. According to the 2019 China 
Health Statistics Yearbook, the cause-specific deathsincluding COPD, IHD, stroke and LC in adults above 60 years old were $98 \%, 92 \%, 97 \%$ and $86 \%$ higher than those of the young adults [41]. As of the rapid population aging [42], future research should quantify the health burden of air pollution by jointly accounting for the effects of population aging[43]. Moreover, given the augmented health burden by changes in the total population and age structure, more emission reduction will be expected in the future. A limitation of our study was that we assumed an unchanged baseline mortality rate because high-resolution or subnational baseline mortality rate projection is not available. Thus it was difficult to predict the future improvement for living conditions and health services at a high spatial resolution.

Some studies have suggested that the adverse health consequences of $\mathrm{PM}_{2.5}$ and $\mathrm{O}_{3}$ pollution have placed a huge burden on economic development $[12,44-46]$. Li et al (2017) [46] found that the the economic loss caused by smoke particulate matter (SPM) in 2012 was US\$8882.4 million (95\% CI: $3574.4,13034.2$ ) and $0.1 \%$ of the total GDP in China. The World Bank estimated \$35 billion income losses in China due to premature death by $\mathrm{PM}_{2.5}$ in 2010 [44] and $\$ 7.6$ billion economic loss caused by $\mathrm{O}_{3}$ in 2016 [11]. This is consistent with our finding at baseline year. However, few studies investigated dynamic changes of the impact of $\mathrm{PM}_{2.5}$ and $\mathrm{O}_{3}$ on the economic burden. Thus, our resutls may not be directly comparable with other studies. Our study results may be relatively high due to the use of the WTP method.

We observed that even under RCP8.5, $\mathrm{PM}_{2.5}$ showed a decreasing trend by 2050 , whereas $\mathrm{PM}_{2.5}$ under RCP6.0 showed an increasing trend. This was due to the increased 
in $\mathrm{SO}_{2}, \mathrm{NOx}, \mathrm{BC}$ and $\mathrm{OC}$ emissions under the RCP scenario by 2050, as shown in figure S5. It should be noted that although the $\mathrm{PM}_{2.5}$ concentration in the RCP6.0 scenario did not ease from 2010 to 2050 , its concentration began to decline sharply after 2050. This is consistent with the time evolution of the regional anthropogenic and biomass combustion emissions 1850-2100 used in Coupled Model Intercomparison Project Phase 5 (CMIP5), which showed in Figure 8.SM.1 in Supplementary Material of Chapter 8 of IPCC (2013) [47].

\section{Conclusions}

Overall, we found that the future death burden due to long-term exposure to $\mathrm{PM}_{2.5}$ and $\mathrm{O}_{3}$ pollution in China will decrease by 2050 under RCP2.6, RCP4.5 and RCP8.5. The increase in the number of deaths caused by the change in population size offset some of the benefits brought by the reduction in air pollution from 2010 to 2050 . Our estimates suggested increasing economic burden due to $\mathrm{PM}_{2.5}$ and $\mathrm{O}_{3}$ exposure in 2010 and a $60.91 \%$ cost can be avoided in the RCP4.5. According to the difference in the future trend and the magnitude of the death toll under the RCP scenarios, it is necessary to adopt more active air pollution emission mitigation measures to ensure that more premature deaths and the associated economic impacts were effectively avoided.

\section{Ethics approval and consent to participate}

Not applicable

\section{Consent for publication}


Not applicable.

397

398

399

400

401

402

403

\section{Availability of data and materials}

The datasets used and/or analysed during the current study are available from the corresponding author on reasonable request.

\section{Competing interests}

The authors declare that they have no competing interests.

\section{Funding}

This work was supported by the National Natural Science Foundation of China (Grant No. 41675125, 41705102, and 41975162); and the National Key Research and Development Program of China (2018YFC0213802); M.Q. acknowledges support from the Startup Fund for Talent at NUIST; M.W. acknowledges support from the Startup Fund for Talent at UB.

\section{Authors' contributions}

J.H., Y.W. and M.W. designed the research and developed the methodology, Y.W. carried out the data analysis and led the writing; J.H. provided supervision and acquired the funding; J.Z. and H.L. assisted in data collection; J.L., M.Q., K.C. contributed significant comments and editing of the paper.

\section{Acknowledgements}

Not applicable 


\section{References}

1. Basagana X, Jacquemin B, Karanasiou A, Ostro B, Querol X, Agis D, Alessandrini E, Alguacil J, Artinano B, Catrambone M et al: Short-term

2. Dai L, Zanobetti A, Koutrakis P, Schwartz JD: Associations of fine particulate matter species with mortality in the United States: a multicity time-series analysis. Environ Health Perspect 2014, $122(8)$ :837-842.

3. Laumbach RJ, Kipen HM: Respiratory health effects of air pollution: update on biomass smoke and traffic pollution. J Allergy Clin Immunol 2012, 129 (1) :3-11; quiz 12-13.

4. Jacobson TA, Kler JS, Hernke MT, Braun RK, Meyer KC, Funk WE: Direct human health risks of increased atmospheric carbon dioxide. Nature Sustainability 2019, $2(8): 691-701$.

5. Monier E, Paltsev S, Sokolov A, Chen YH, Gao X, Ejaz Q, Couzo E, Schlosser CA, Dutkiewicz S, Fant C et al: Toward a consistent modeling framework to assess multi-sectoral climate impacts. Nat Commun 2018, 9(1):660.

6. Hu J, Huang L, Chen M, Liao H, Zhang H, Wang S, Zhang Q, Ying Q: Premature Mortality Attributable to Particulate Matter in China: Source Contributions and Responses to Reductions. Environ Sci Technol 2017, 51 (17):9950-9959.

7. Cohen AJ, Brauer M, Burnett R, Anderson HR, Frostad J, Estep K, Balakrishnan K, Brunekreef B, Dandona L, Dandona R et al: Estimates and 25year trends of the global burden of disease attributable to ambient air pollution: an analysis of data from the Global Burden of Diseases Study 2015. Lancet 2017, 389 (10082) :1907-1918.

8. Li T, Zhang Y, Wang J, Xu D, Yin Z, Chen H, Lv Y, Luo J, Zeng Y, Liu Y et al: Al1-cause mortality risk associated with long-term exposure to ambient PM2. 5 in China: a cohort study. Lancet Public Health 2018, 3(10):e470-e477.

9. Lin Y, Jiang F, Zhao J, Zhu G, He X, Ma X, Li S, Sabel CE, Wang H: Impacts of 03 on premature mortality and crop yield loss across China. Atmos Environ 2018, 194:41-47.

10. Centre CNEM: Air Quality Report in 74 Chinese Cities in March and the First half of 20132013.

11. Maji KJ, Ye WF, Arora M, Nagendra SMS: Ozone pollution in Chinese cities: Assessment of seasonal variation, health effects and economic burden. Environ Pollut 2019, 247:792-801.

12. Chen L, Shi M, Gao S, Li S, Mao J, Zhang H, Sun Y, Bai Z, Wang Z: Assessment of population exposure to PM2. 5 for mortality in China and its public health benefit based on BenMAP. Environ Pollut 2017, 221:311-317.

13. Maji KJ, Dikshit AK, Arora M, Deshpande A: Estimating premature mortality attributable to PM2. 5 exposure and benefit of air pollution control policies in China for 2020. Sci Total Environ 2018, 612:683-693. 
14. Wang Q, Wang J, Zhou J, Ban J, Li T: Estimation of PM2 - 5-associated disease burden in China in 2020 and 2030 using population and air quality scenarios: a modelling study. The Lancet Planetary Health 2019, 3(2):e71e80.

15. Colette A, Bessagnet B, Vautard R, Szopa S, Rao S, Schucht S, Klimont Z, Menut L, Clain G, Meleux F et al: European atmosphere in 2050, a regional air quality and climate perspective under CMIP5 scenarios. Atmospheric Chem Phys 2013, 13 (15) :7451-7471.

16. Jiang H, Liao H, Pye HOT, Wu S, Mickley LJ, Seinfeld JH, Zhang XY: Projected effect of 2000-2050 changes in climate and emissions on aerosol levels in China and associated transboundary transport. Atmospheric Chem Phys 2013, 13 (16): 7937-7960.

17. Li K, Liao H, Zhu J, Moch JM: Implications of RCP emissions on future PM2. 5 air quality and direct radiative forcing over China. Journal of Geophysical Research: Atmospheres 2016, $121(21): 12,985-913,008$.

18. Zhu J, Liao H: Future ozone air quality and radiative forcing over China owing to future changes in emissions under the Representative Concentration Pathways (RCPs). Journal of Geophysical Research: Atmospheres 2016, 121 (4) : 1978-2001.

19. Lou S, Liao H, Zhu B: Impacts of aerosols on surface-layer ozone concentrations in China through heterogeneous reactions and changes in photolysis rates. Atmos Environ 2014, 85:123-138.

20. $\mathrm{Mu} \mathrm{Q}$, Liao $\mathrm{H}$ : Simulation of the interannual variations of aerosols in China: role of variations in meteorological parameters. Atmospheric Chem Phys 2014, 14(18):9597-9612.

21. van Vuuren DP, Edmonds J, Kainuma M, Riahi K, Thomson A, Hibbard K, Hurtt GC, Kram T, Krey V, Lamarque J-F et al: The representative concentration pathways: an overview. Clim Change 2011, $109(1-2): 5-31$.

22. Linares C, Falcon I, Ortiz C, Diaz J: An approach estimating the short-term effect of N02 on daily mortality in Spanish cities. Environ Int 2018, $116: 18-28$.

23. EPA. US: Integrated Science Assessment (ISA) for Ozone and Related Photochemical 0xidants (External Review Draft). 2020, U. S. Environmental Protection Agency, Washington, DC, EPA/600/R-19/093.

24. Health Mo: 2011 China Health Statistics Yearbook: China Union Medical University Press; 2011.

25. Burnett R, Chen H, Szyszkowicz M, Fann N, Hubbe11 B, Pope CA, 3rd, Apte JS, Brauer M, Cohen A, Weichenthal S et al: Global estimates of mortality associated with long-term exposure to outdoor fine particulate matter. Proc Nat1 Acad Sci U S A 2018, 115 (38) :9592-9597.

26. Burnett RT, Pope CA, 3rd, Ezzati M, Olives C, Lim SS, Mehta S, Shin HH, Singh G, Hubbell B, Brauer M et al: An integrated risk function for estimating the global burden of disease attributable to ambient fine particulate matter exposure. Environ Health Perspect 2014, $122(4): 397-403$. 
27. Lim SS, Vos T, Flaxman AD, Danaei G, Shibuya K, Adair-Rohani H, Amann M, Anderson HR, Andrews KG, Aryee M et al: A comparative risk assessment of burden of disease and injury attributable to 67 risk factors and risk factor clusters in 21 regions, 1990-2010: a systematic analysis for the Global Burden of Disease Study 2010. Lancet 2012, 380 (9859) :2224-2260.

28. Jerrett M, Burnett RT, Pope CA, 3rd, Ito K, Thurston G, Krewski D, Shi Y, Calle E, Thun M: Long-term ozone exposure and mortality. N Engl J Med 2009, 360 (11) : 1085-1095.

29. Turner MC, Jerrett M, Pope CA, 3rd, Krewski D, Gapstur SM, Diver WR, Beckerman BS, Marshall JD, Su J, Crouse DL et al: Long-Term Ozone Exposure and Mortality in a Large Prospective Study. Am J Respir Crit Care Med 2016, 193 (10) : 1134-1142.

30. Chen F, Yamashita K, Kurokawa J, Klimont Z: Cost-Benefit Analysis of Reducing Premature Mortality Caused by Exposure to Ozone and PM2. 5 in East Asia in 2020. Water, Air, Soil Pollut 2015, $226(4)$.

31. Xie Y, Dai H, Dong H, Hanaoka T, Masui T: Economic Impacts from PM2. 5 Pollution-Related Health Effects in China: A Provincial-Level Analysis. Environ Sci Technol 2016, 50 (9):4836-4843.

32. Xie Y, Dai H, Zhang Y, Wu Y, Hanaoka T, Masui T: Comparison of health and economic impacts of PM2.5 and ozone pollution in China. Environ Int 2019, $130: 104881$.

33. Chen K, Fiore AM, Chen R, Jiang L, Jones B, Schneider A, Peters A, Bi J, Kan H, Kinney PL: Future ozone-related acute excess mortality under climate and population change scenarios in China: A modeling study. PLoS Med 2018, $15(7)$ : e1002598.

34. Lim CC, Hayes RB, Ahn J, Shao Y, Silverman DT, Jones RR, Garcia C, Bel1 ML, Thurston GD: Long-Term Exposure to Ozone and Cause-Specific Mortality Risk in the United States. Am J Respir Crit Care Med 2019, 200 (8):1022-1031.

35. Kazemiparkouhi F, Eum KD, Wang B, Manjourides J, Suh HH: Long-term ozone exposures and cause-specific mortality in a US Medicare cohort. J Expo Sci Environ Epidemiol 2020, 30(4):650-658.

36. Zhang Q, Zheng Y, Tong D, Shao M, Wang S, Zhang Y, Xu X, Wang J, He H, Liu W et al: Drivers of improved PM2. 5 air quality in China from 2013 to 2017. Proc Nat1 Acad Sci U S A 2019, 116(49):24463-24469.

37. Liu Y, Wang T: Worsening urban ozone pollution in China from 2013 to 2017 - Part 1: The complex and varying roles of meteorology. Atmospheric Chem Phys 2020, 20(11):6305-6321.

38. Wang S, Luo Y, Wen X, Huang J: New generation of scenarios of greenhouse gas emission. Adv Clim Chang Res 2012, 8(4):3.5-307.

39. Watts N, Adger WN, Agnolucci P, Blackstock J, Byass P, Cai W, Chaytor S, Colbourn T, Collins M, Cooper A et al: Health and climate change: policy responses to protect public health. Lancet 2015, 386 (10006):1861-1914.

40. Wang Y, Zu Y, Huang L, Zhang H, Wang C, Hu J: Associations between daily outpatient visits for respiratory diseases and ambient fine particulate 
matter and ozone levels in Shanghai, China. Environ Pollut 2018, 240:754763.

41. China. MoHotPsRo: China Health Statistics Yearbook. 2014.

42. Jones B, 0' Neill BC: Spatially explicit global population scenarios consistent with the Shared Socioeconomic Pathways. Environmental Research Letters 2016, $11(8)$ :084003.

43. Chen K, Vicedo-Cabrera AM, Dubrow R: Projections of Ambient Temperatureand Air Pollution-Related Mortality Burden Under Combined Climate Change and Population Aging Scenarios: a Review. Curr Environ Health Rep 2020, 7 (3) : 243-255.

44. Bank W: The cost of air pollution : strengthening the economic case for action. Washington, DC : World Bank Group 2016.

45. Nansai K, Tohno S, Chatani S, Kanemoto K, Kurogi M, Fujii Y, Kagawa S, Kondo Y, Nagashima F, Takayanagi W et al: Affluent countries inflict inequitable mortality and economic loss on Asia via PM2. 5 emissions. Environ Int 2020, 134:105238.

46. Li C, Hu Y, Zhang F, Chen J, Ma Z, Ye X, Yang X, Wang L, Tang X, Zhang R et al: Multi-pollutant emissions from the burning of major agricultural residues in China and the related health-economic effects. Atmospheric Chem Phys 2017, 17 (8): 4957-4988.

47. Myhre G, D. Shindell, F. -M. Bréon, W. Collins, J. Fuglestvedt, J. Huang, D. Koch, J.-F. Lamarque, D. Lee, B. Mendoza,, T. Nakajima AR, G. Stephens, T. Takemura and H. Zhang: Anthropogenic and Natural Radiative Forcing. In: Climate Change 2013: The Physical Science Basis. Contribution of Working Group I to the Fifth Assessment Report of the Intergovernmental Panel on Climate Change [Stocker, T.F., D. Qin, G. -K. Plattner, M. Tignor, S. K. Allen, J. Boschung, A. Nauels, Y. Xia, V. Bex and P. M. Midgley (eds.)]. Cambridge University Press, Cambridge, United Kingdom and New York, NY, USA 2013.

\section{Figures}



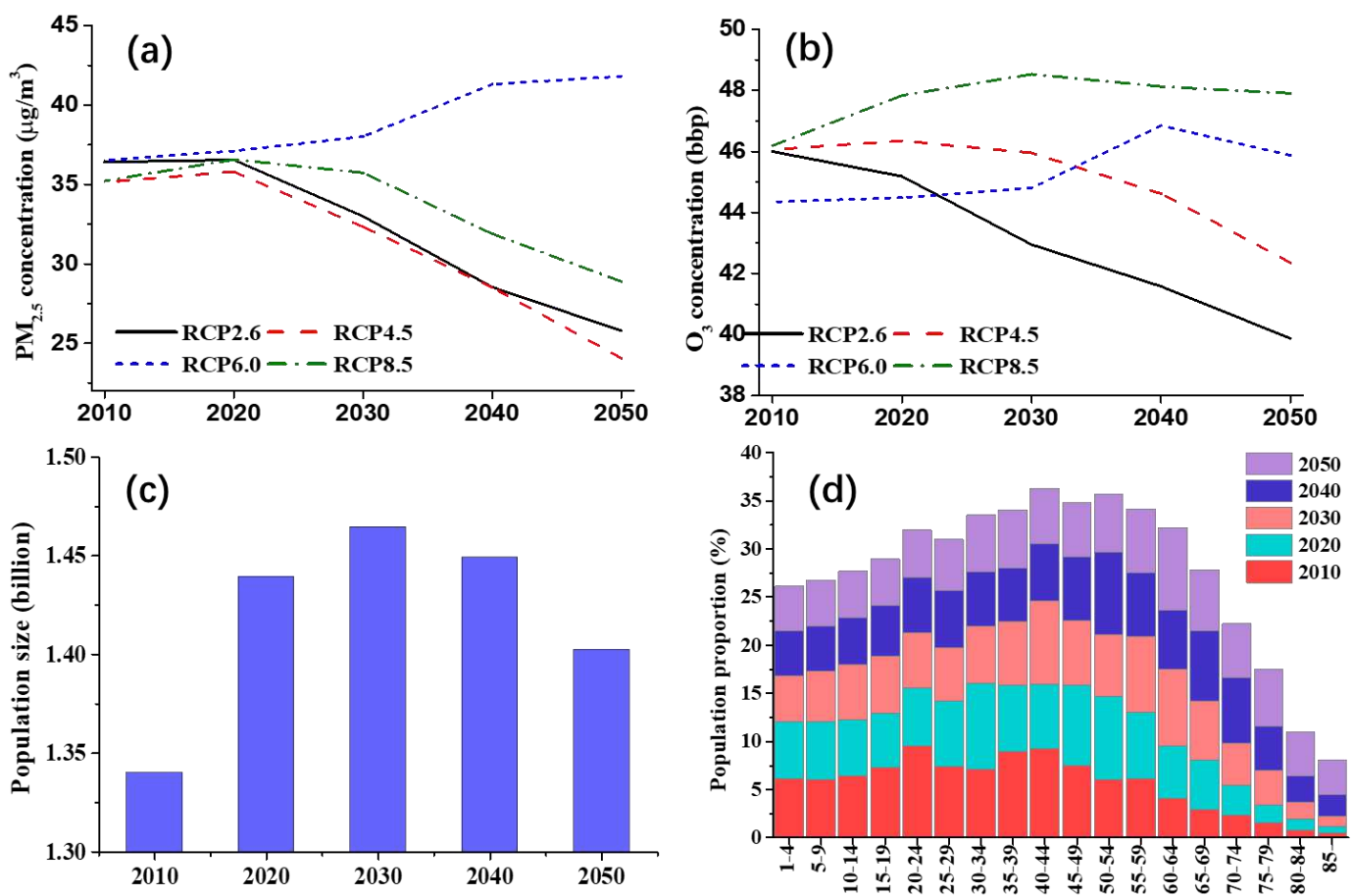

Figure 1. The concentration of $\mathrm{PM}_{2.5}$ (a) and $\mathrm{O}_{3}$ (b) change from 2010 to 2050 under RCP scenarios. Projected changes in exposed population size (c) of all ages in China

from 2010 to 2050. Demography transition change (d) from 2010 to 2050.
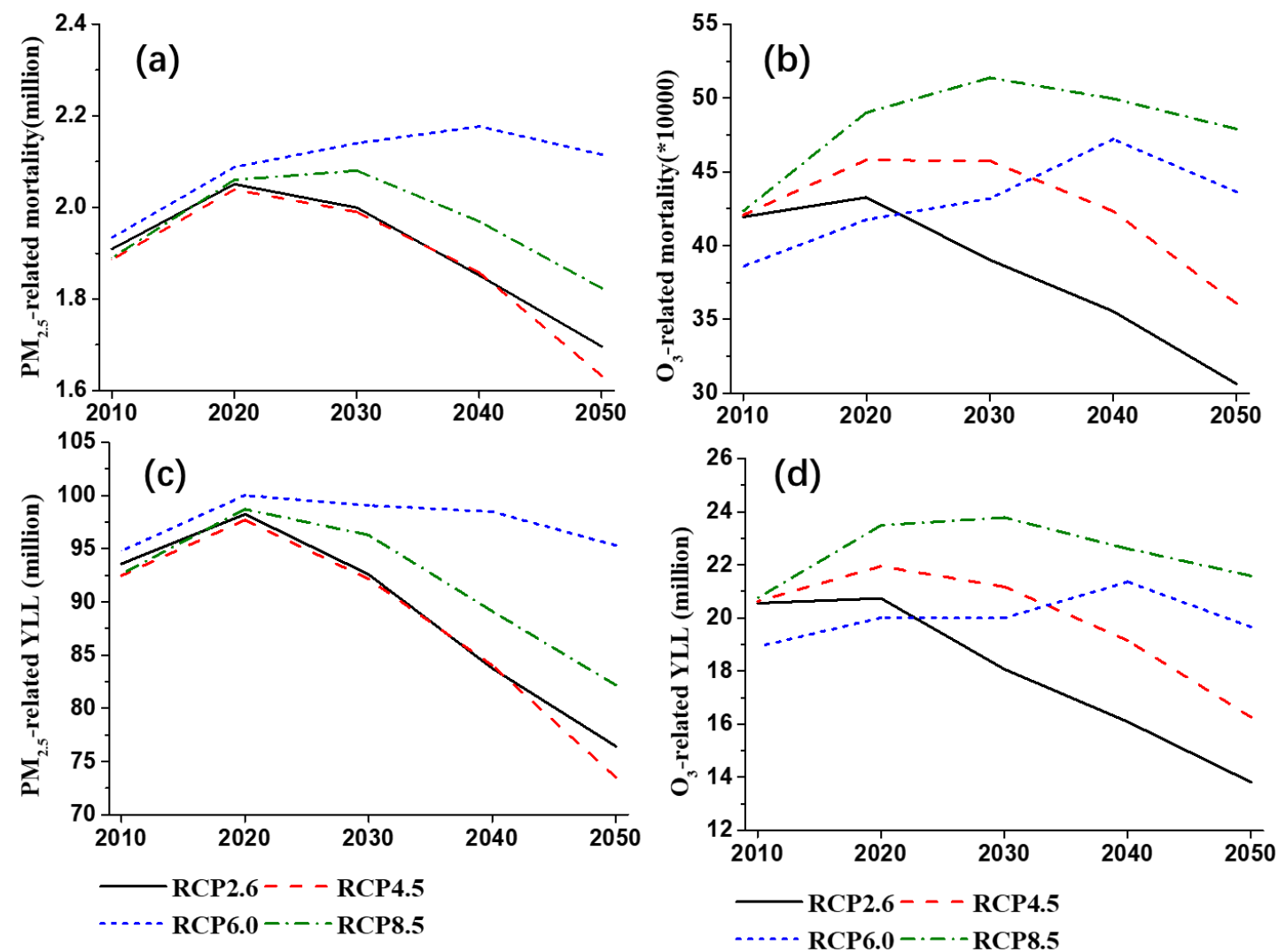

Figure 2. The mortality (a-b) and YLL(c-d) caused by $\mathrm{PM}_{2.5}$ and $\mathrm{O}_{3}$ from 2010 to 2050 under four RCP scenarios. 


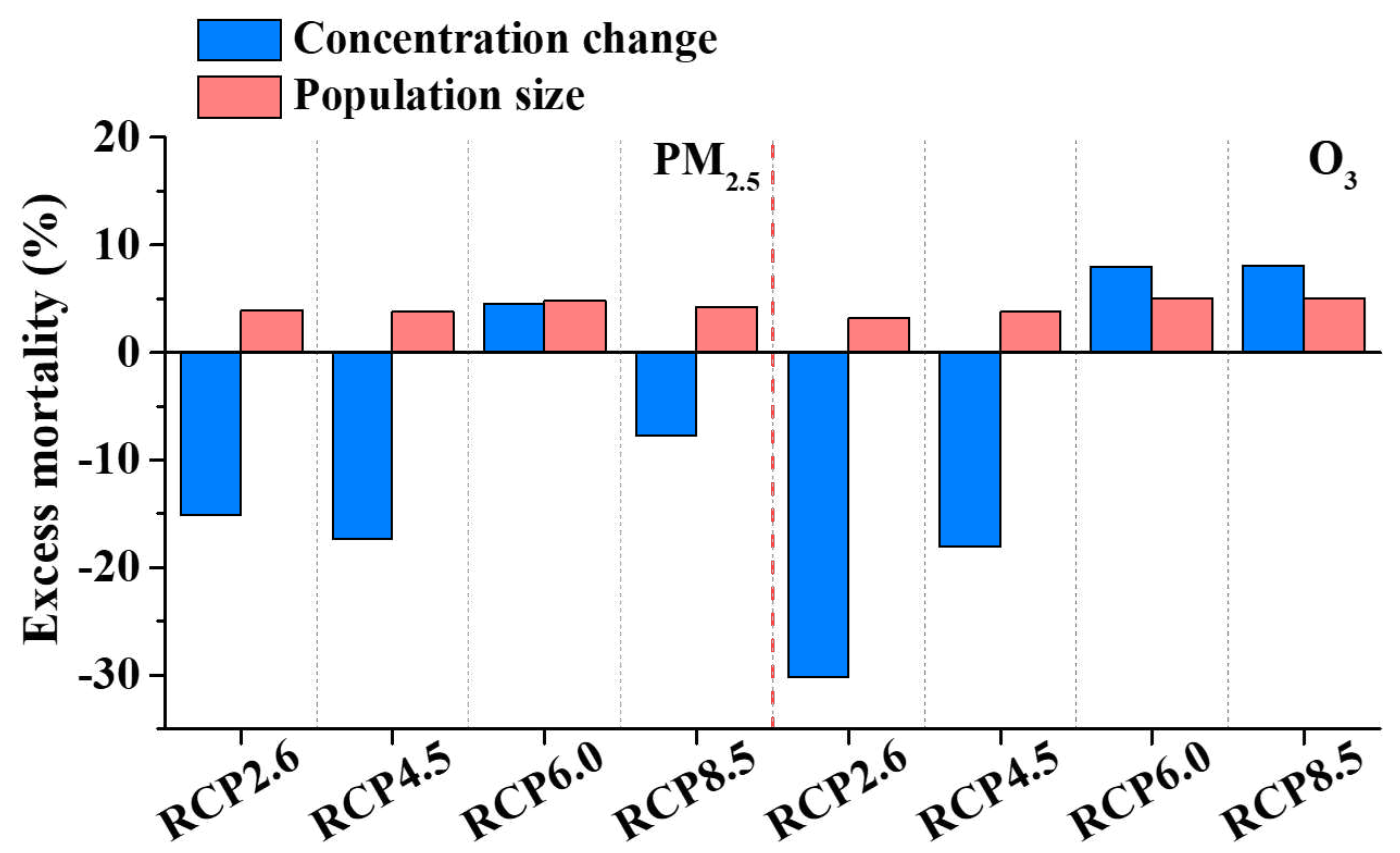

Figure 3. The impact of concentration and population size changes on $\mathrm{PM}_{2.5}$-related and $\mathrm{O}_{3}$-related premature death reduction from 2010 to 2050 under four RCP scenarios. 


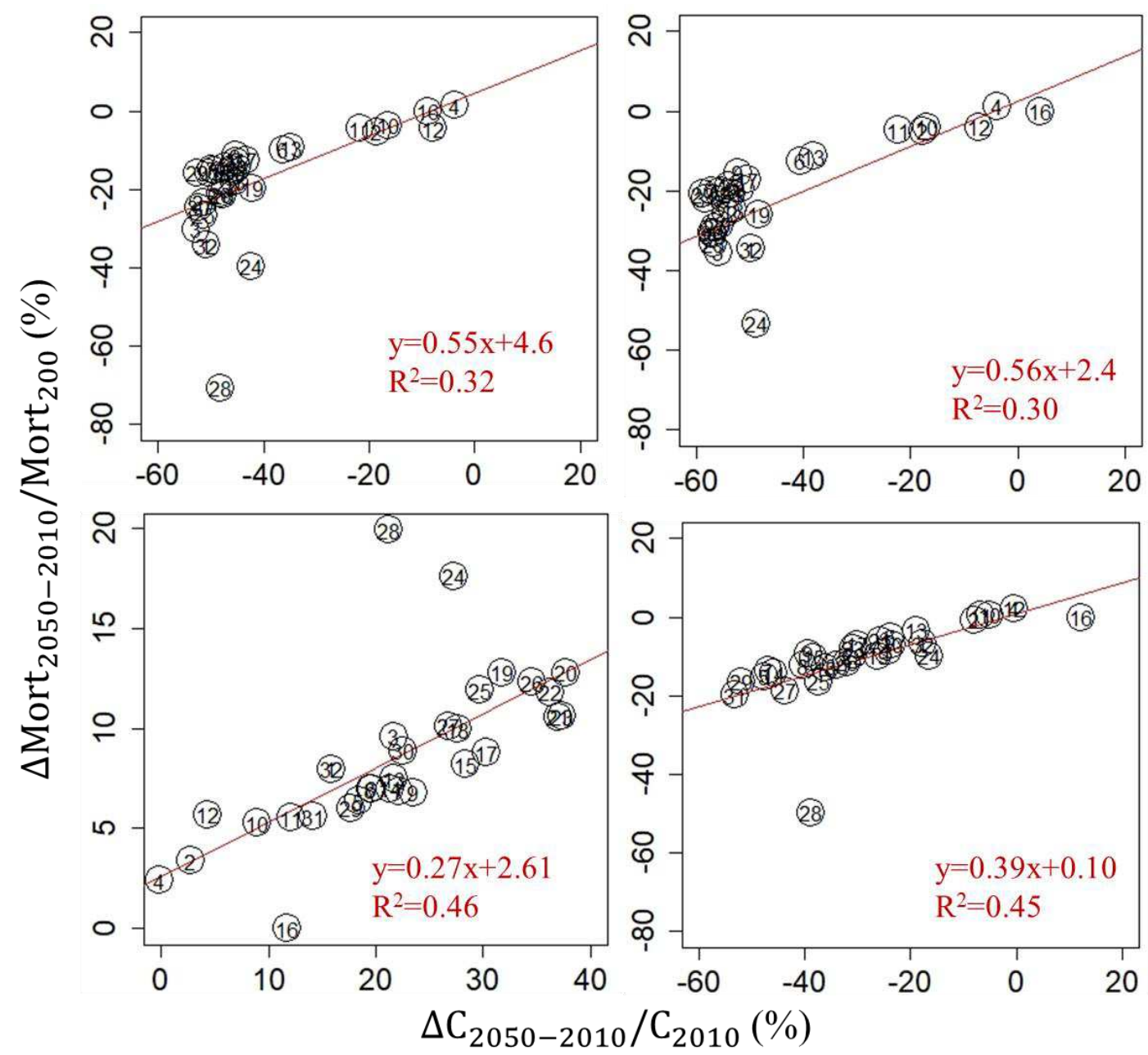

593 Figure 4. Scatter plots of the ratio of $\mathrm{PM}_{2.5}$ concentration difference to baseline concentration and $\mathrm{PM}_{2.5}$ death rate difference to baseline ratio in 2050 compared to 2010 for different provinces under RCP2.6 (a), RCP4.5 (b), RCP6.0(c) and RCP8.5 (d). The provinces are numerically coded as 1- Heilongjiang, 2- Neimeng, 3- Jilin, 4Xinjiang, 5- Beijing, 6- Shanxi, 7- Shandong, 8- Hebei, 9- Henan, 10- Gansu, 11Ningxia, 12- Qinghai, 13- Shaanxi, 14- Jiangsu, 15- Anhui, 16- Tibet, 17- Hubei, 18 Zhejiang, 19- Sichuan, 20- Guizhou, 1- Chongqing, 22- Jiangxi, 23- Hunan, 24Yunnan, 25- Fujian, 26- Guangxi, 27- Guangdong, 28- Hainan, 29- Tianjin, 30Liaoning, 31- Shanghai. 

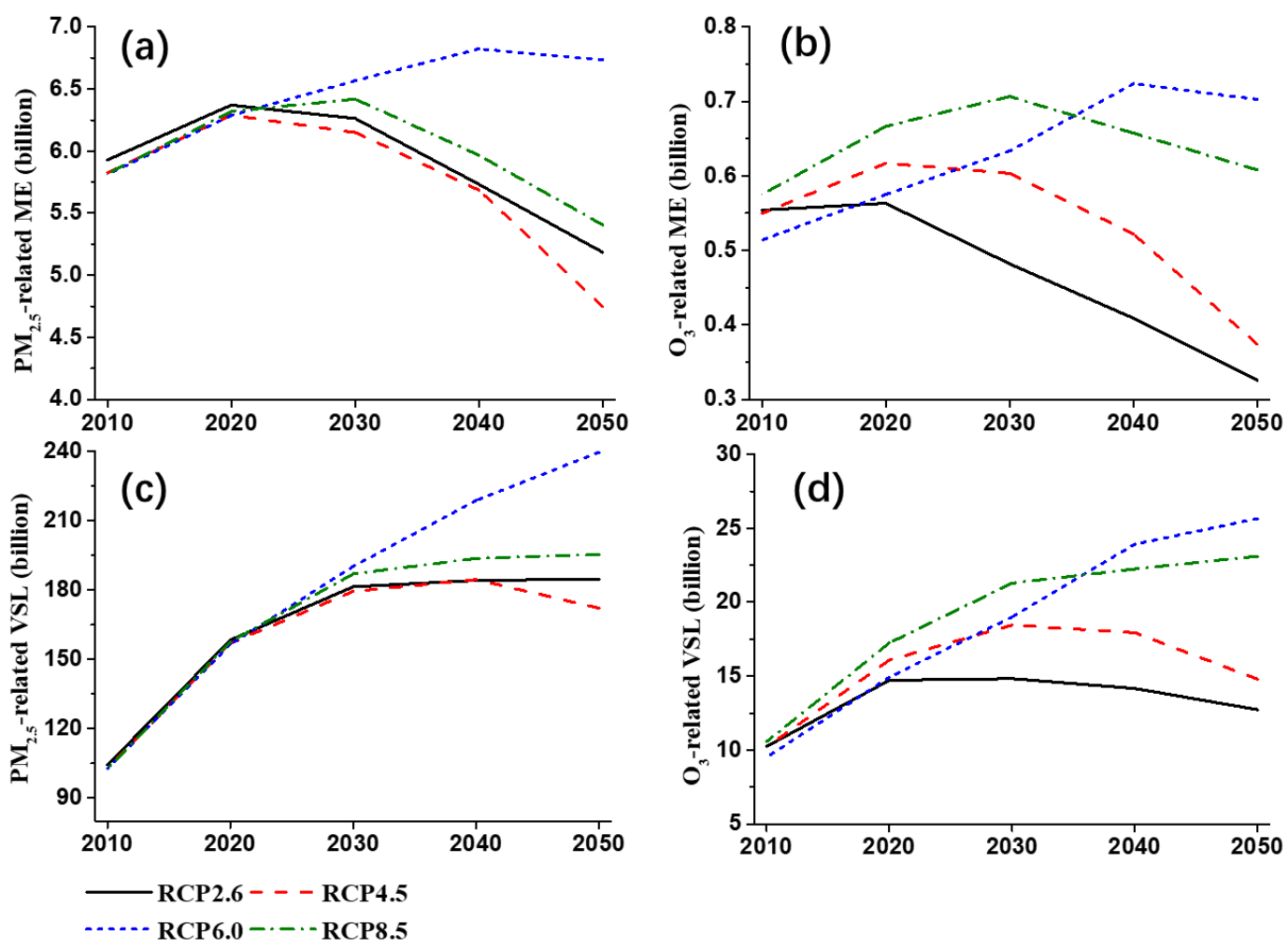

602

Figure 5. The ME (a-b) and VSL (c-d) caused by $\mathrm{PM}_{2.5}$ and $\mathrm{O}_{3}$ from 2010 to 2050 604 under four RCP scenarios.

605 
Figures
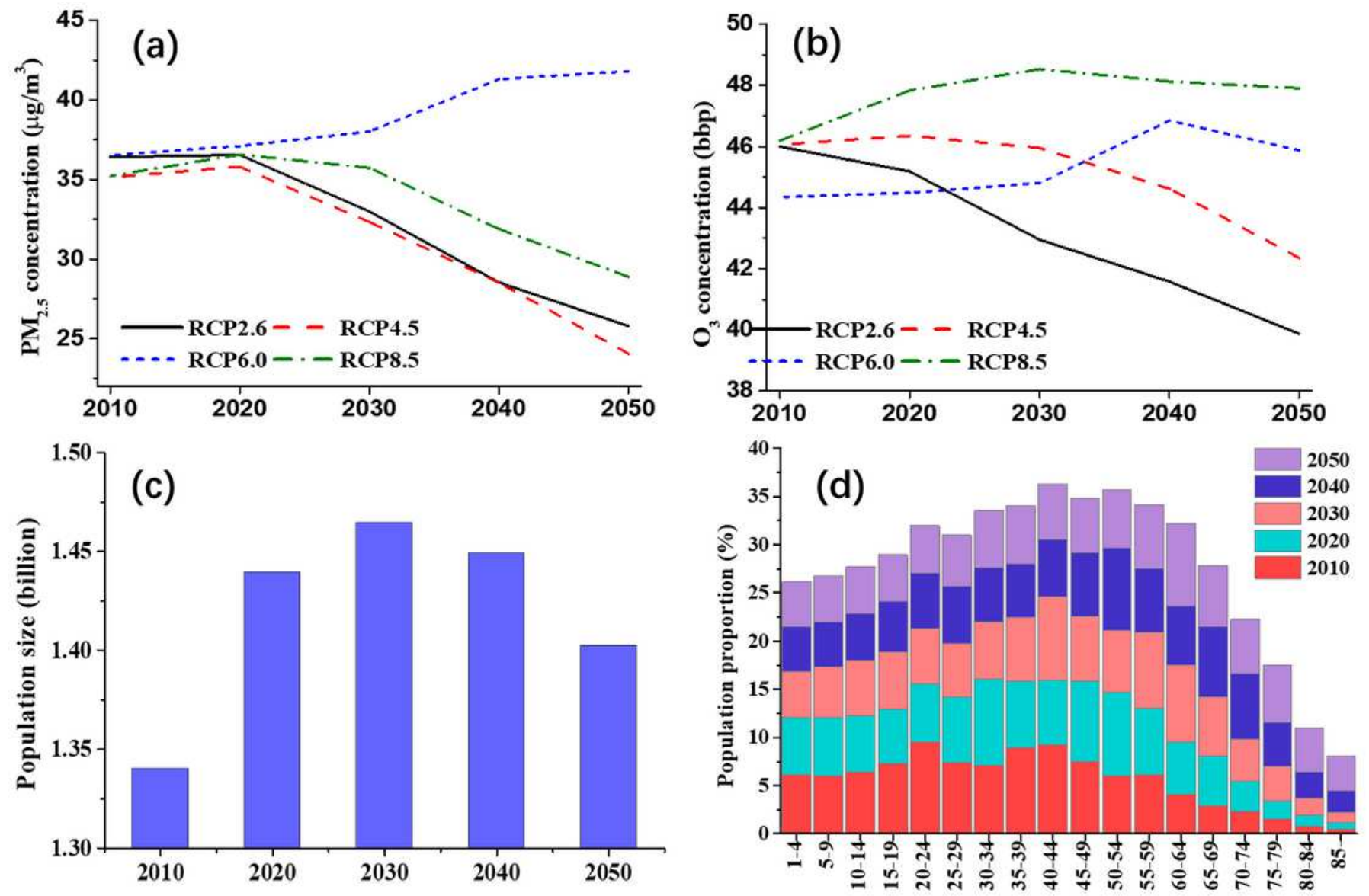

\section{Figure 1}

The concentration of PM2.5 (a) and 03 (b) change from 2010 to 2050 under RCP scenarios. Projected changes in exposed population size (c) of all ages in China from 2010 to 2050. Demography transition change (d) from 2010 to 2050. 

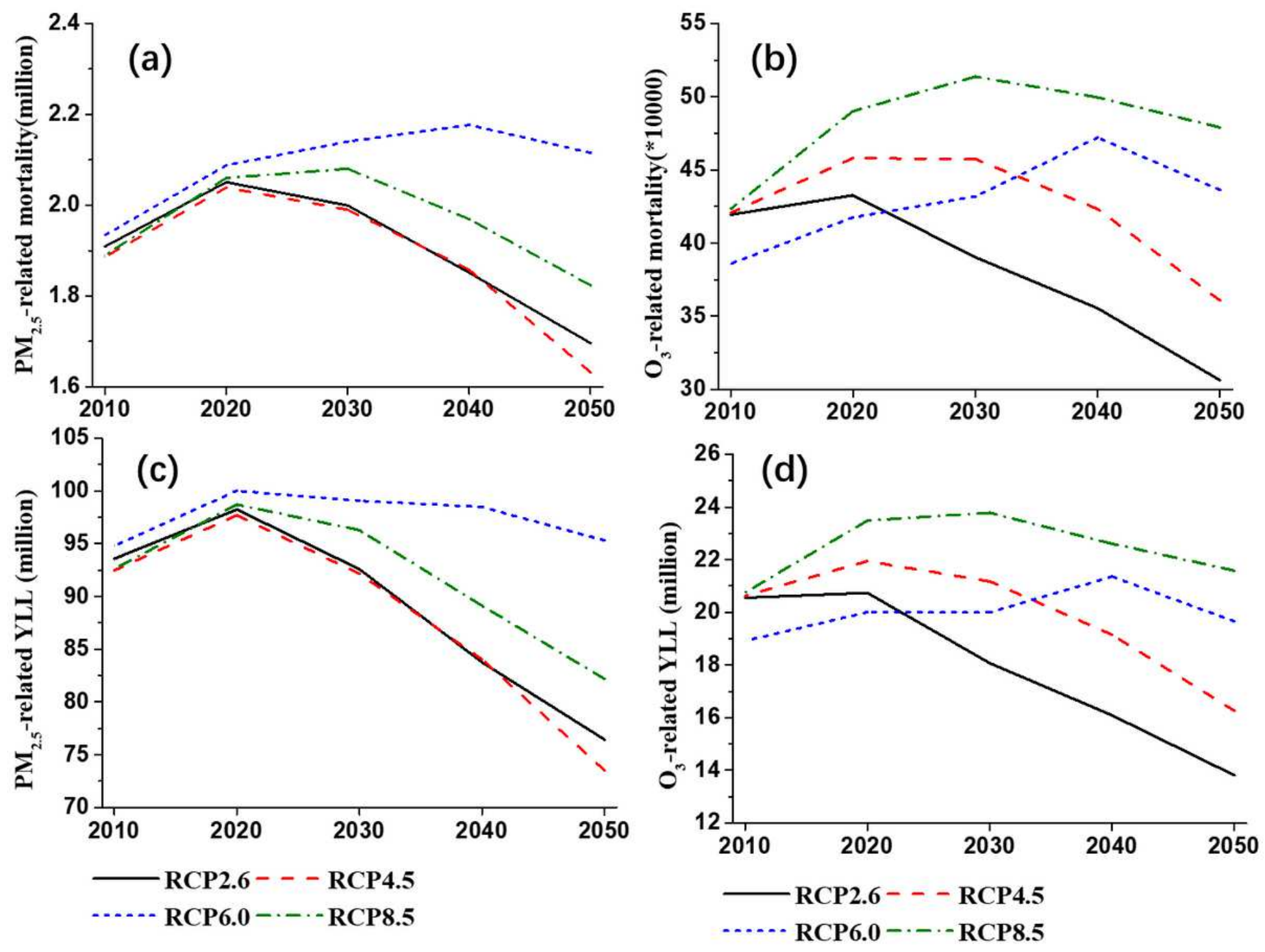

Figure 2

The mortality (a-b) and YLL(c-d) caused by PM2.5 and 03 from 2010 to 2050 under four RCP scenarios. 


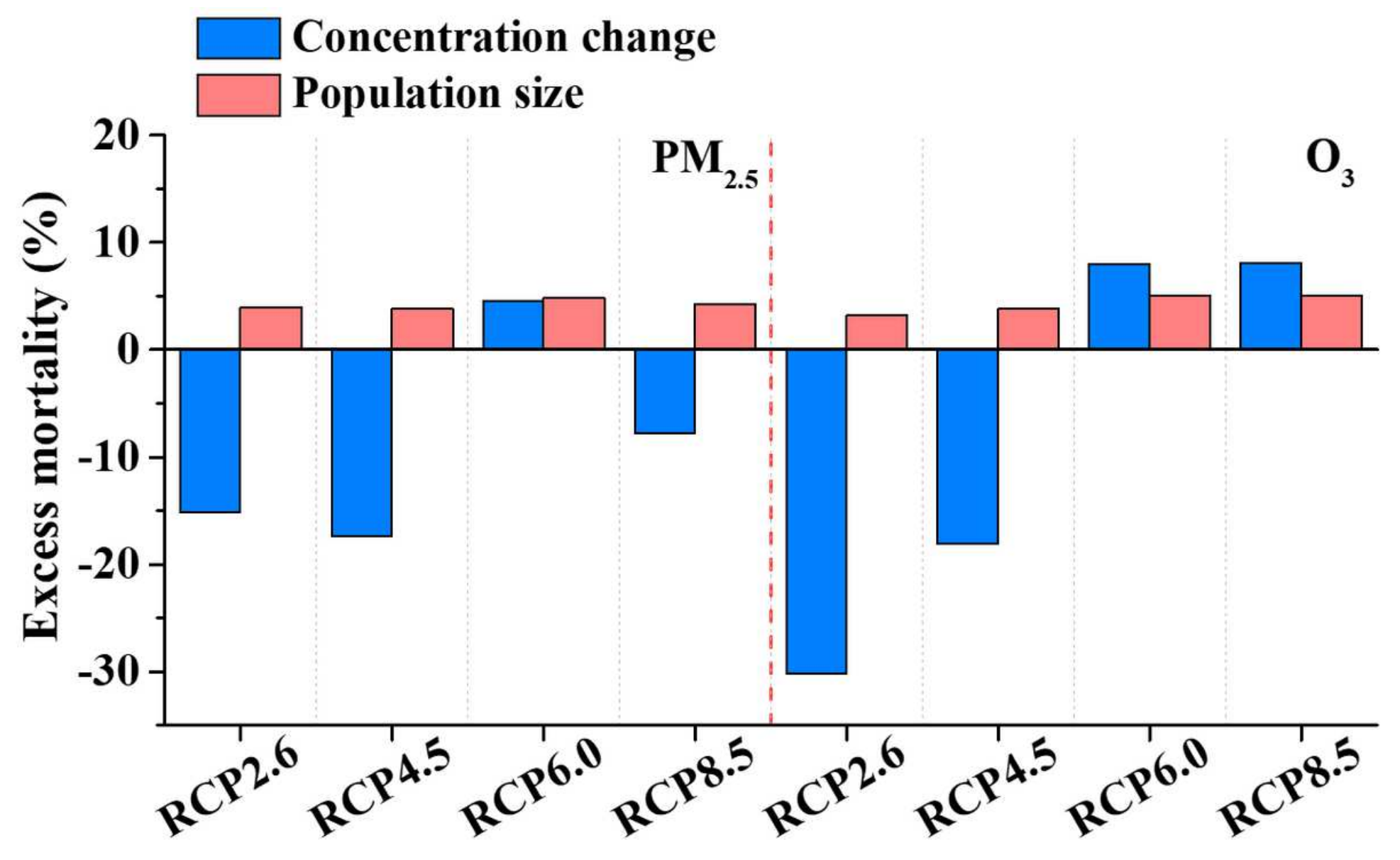

Figure 3

The impact of concentration and population size changes on PM2.5-related and 03-related premature death reduction from 2010 to 2050 under four RCP scenarios. 


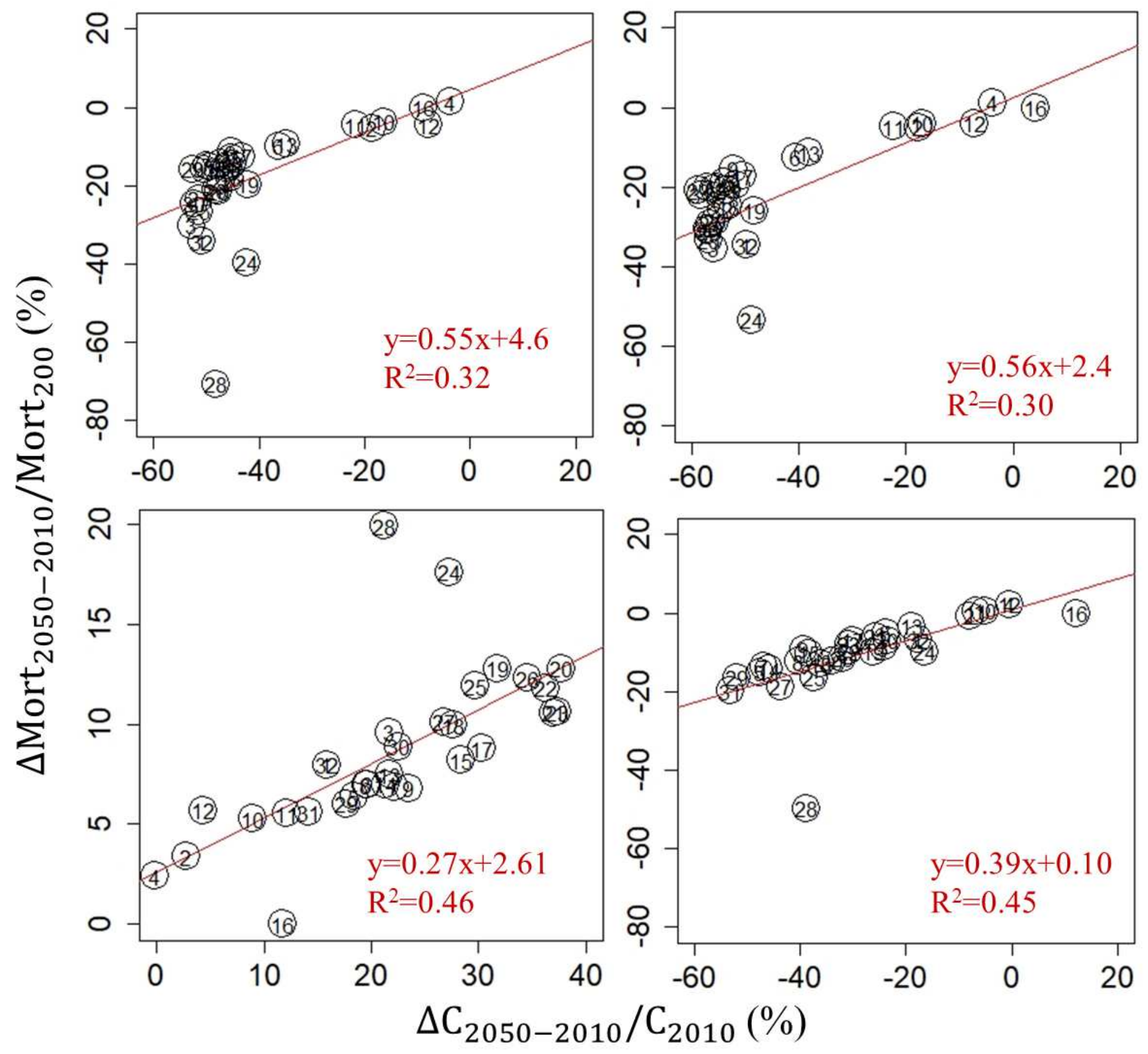

Figure 4

Scatter plots of the ratio of PM2.5 concentration difference to baseline concentration and PM2.5 death rate difference to baseline ratio in 2050 compared to 2010 for different provinces under RCP2.6 (a), RCP4.5 (b), RCP6.0(c) and RCP8.5 (d). The provinces are numerically coded as 1- Heilongjiang, 2Neimeng, 3- Jilin, 4- Xinjiang, 5- Beijing, 6- Shanxi, 7- Shandong, 8- Hebei, 9- Henan, 10- Gansu, 11Ningxia, 12- Qinghai, 13- Shaanxi, 14- Jiangsu, 15- Anhui, 16- Tibet, 17- Hubei, 18- Zhejiang, 19- Sichuan, 20- Guizhou, 1- Chongqing, 22- Jiangxi, 23- Hunan, 24- Yunnan, 25- Fujian, 26- Guangxi, 27- Guangdong, 28- Hainan, 29- Tianjin, 30- Liaoning, 31- Shanghai. 

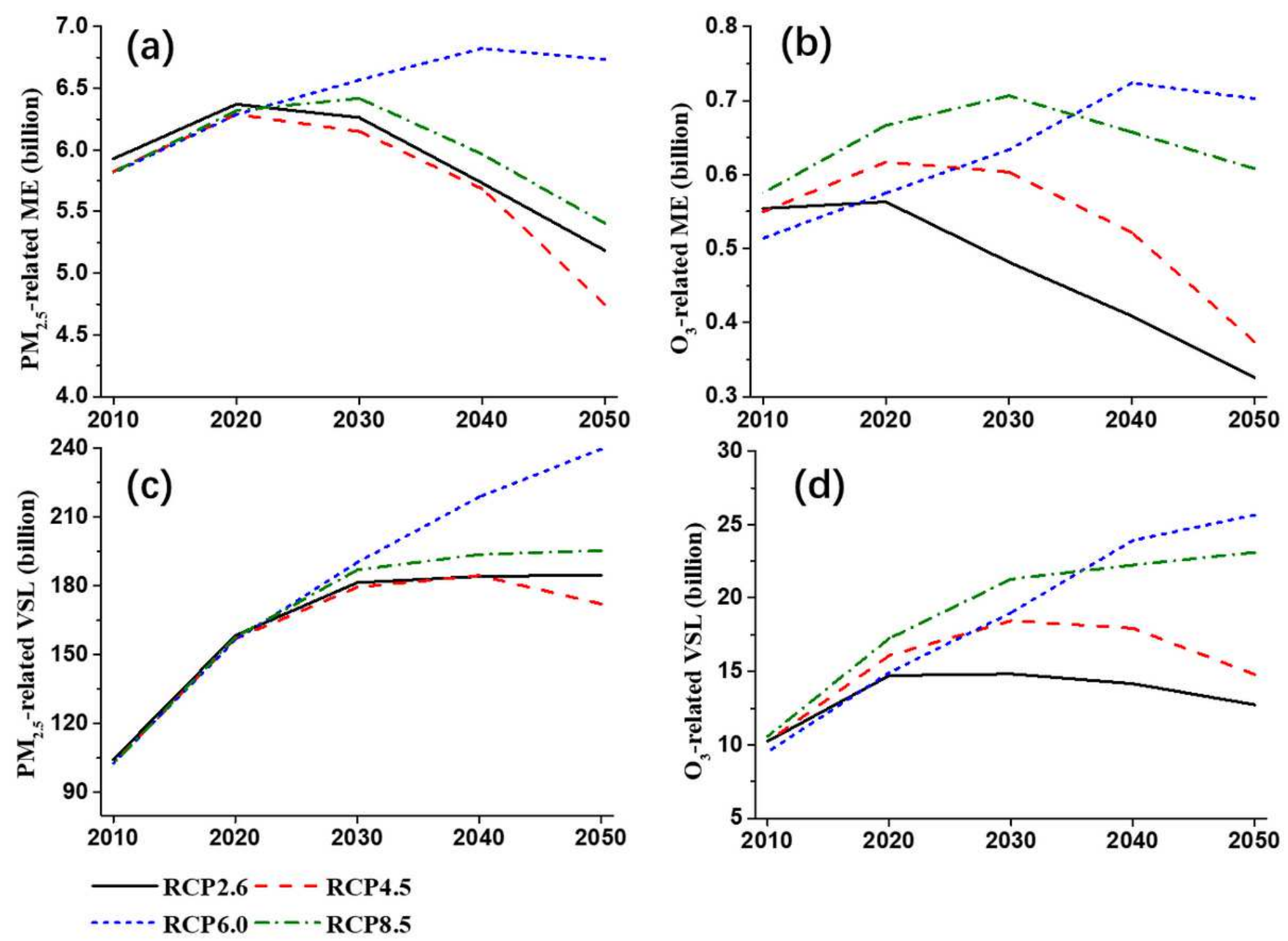

Figure 5

The ME (a-b) and VSL (c-d) caused by PM2.5 and 03 from 2010 to 2050 under four RCP scenarios.

\section{Supplementary Files}

This is a list of supplementary files associated with this preprint. Click to download.

- Supplementary.docx 